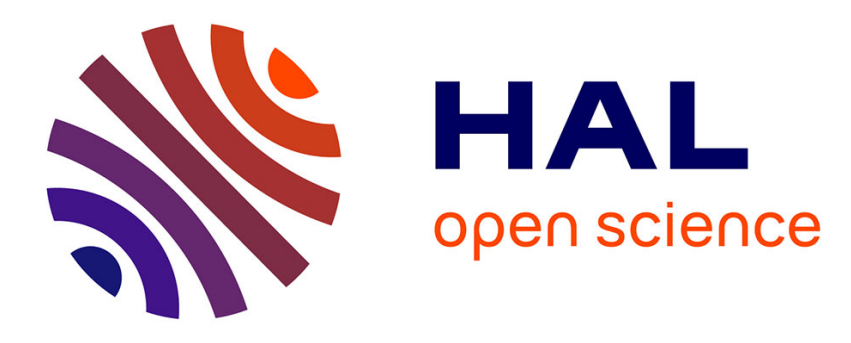

\title{
Polyarthrite chronique destructrice au cours de la maladie de Whipple
}

\author{
Sara El Rharras, Emeline Minichiello, Luca Semerano
}

\section{To cite this version:}

Sara El Rharras, Emeline Minichiello, Luca Semerano. Polyarthrite chronique destructrice au cours de la maladie de Whipple. Revue du Rhumatisme, 2019, 86, pp.99 -. 10.1016/j.rhum.2018.11.001 . hal-03486228

\section{HAL Id: hal-03486228 \\ https://hal.science/hal-03486228}

Submitted on 20 Dec 2021

HAL is a multi-disciplinary open access archive for the deposit and dissemination of scientific research documents, whether they are published or not. The documents may come from teaching and research institutions in France or abroad, or from public or private research centers.
L'archive ouverte pluridisciplinaire HAL, est destinée au dépôt et à la diffusion de documents scientifiques de niveau recherche, publiés ou non, émanant des établissements d'enseignement et de recherche français ou étrangers, des laboratoires publics ou privés.

\section{다)(1) $(5$}

Distributed under a Creative Commons Attribution - NonCommercial| 4.0 International 


\section{Polyarthrite chronique destructrice au cours de la maladie de Whipple}

\section{Sara El Rharras ${ }^{1,2}$, Emeline Minichiello ${ }^{1,3,4}$, Luca Semerano $o^{1,3,4}$}

1 Service de Rhumatologie, Groupe hospitalier Avicenne -Jean Verdier- René Muret, Assistance Publique-Hôpitaux de Paris (AP-HP) 125, rue de Stalingrad 93017 Bobigny, France.

2 CHU Muhammad VI, Hôpital Arrazi, Service de Rhumatologie, Marrakech, Maroc.

3 Inserm UMR 1125, 1, rue de Chablis 93017 Bobigny, France.

4 Sorbonne Paris Cité - Université Paris 13, 1, rue de Chablis 93017 Bobigny France.

Auteur correspondant :

Luca Semerano, Service de Rhumatologie, Groupe hospitalier Avicenne -Jean Verdier- René Muret, Assistance Publique-Hôpitaux de Paris (AP-HP) 125, rue de Stalingrad 93017 Bobigny, France.

luca.semerano@aphp.fr 
Radiographie des mains montrant une atteinte destructrice et une ankylose bilatérales des os du carpe ainsi qu'un pincement articulaire du carrefour radio-ulno-carpien chez une femme de 39 ans souffrant de la maladie de Whipple (MW) mais traitée pendant 11 ans pour une polyarthrite rhumatoïde (PR) (Figure 1). Les articulations métacarpo-phalangiennes et interphalangiennes sont épargnées comme déjà rapporté dans la maladie de Whipple [1]. Une arthrite destructrice du poignet droit est également observée. Le diagnostic de PR séronégative, ACPA-négative avait été retenu chez cette patiente. La réponse aux traitements de fond classiques (salazopyrine puis leflunomide et enfin méthotrexate) et ultérieurement aux traitements biologiques (tocilizumab puis abatacept) s'est avérée inadéquate. La PCR et les biopsies duodénale et ganglionnaire ont confirmé le diagnostic de MW.

\section{Références}

1 Puéchal X. Whipple's arthritis. Joint Bone Spine. 2016;83:631-635. 
